\title{
Unfinished Business: The Missing Skills
}

Andrew S. Gibbons III

Brigham Young University, andy_gibbons@byu.edu

Follow this and additional works at: https://scholarsarchive.byu.edu/facpub

Part of the Educational Methods Commons

\section{BYU ScholarsArchive Citation}

Gibbons, Andrew S. III, "Unfinished Business: The Missing Skills" (2018). Faculty Publications. 2969. https://scholarsarchive.byu.edu/facpub/2969

This Working Paper is brought to you for free and open access by BYU ScholarsArchive. It has been accepted for inclusion in Faculty Publications by an authorized administrator of BYU ScholarsArchive. For more information, please contact ellen_amatangelo@byu.edu. 


\title{
Unfinished Business: The Missing Skills
}

\author{
Andrew S. Gibbons \\ Brigham Young University \\ Presented at the \\ AECT Summer Research Symposium $2018^{1}$ \\ July 16-17 \\ Bloomington, Indiana
}

\begin{abstract}
Two taxonomies of instructional goals (Bloom, Gagné) are revisited, asking why the design community at large treats them as "received wisdom", while at the same time their authors and colleagues treat(ed) them as unfinished business and continued to modify them. The question is raised as to the possibility of finding a resolution of their differences. The thesis is advanced that both consist of lower-level performances subordinate to and leading to skilled performance, which may supply a unifying principle. The proposition is advanced that we should look for ways of reconciling and integrating their differences. Using skilled performance as the superclass of both is suggested as a means of achieving this.
\end{abstract}

Keywords: Instructional goals, goal taxonomies, learning goals, instructional objectives, skill learning, skill

\section{The Fragmentation of Goals}

In the dust and smoke of academic war, it is easy to lose our orientation. In the unnecessary and unfinished battle between the objectives taxonomies of Bloom and Gagné, it is possible that our vision has been obscured, and we have lost perspective on the original problem, which was to systematically summarize the elements of human performance so that complex learning experiences could be organized and ordered logically. Neither taxonomy ever really reached a final state, and therefore they represent unfinished academic business. What each did accomplish was to use a particular decomposition logic to identify fragments of a larger but seldom acknowledged phenomenon of human behavior, the competent skilled performance. Skill as a type of learning outcome has been overlooked in the dust and smoke raised by the squabble over taxonomic details. This paper makes the case for revisiting the unfinished taxonomy business in search of a unifying view based on a higher organizing principle of human performance: fluid and fluent skill. From this perspective, it is easy to see that the taxonomies are much closer in substance than previously thought and that they can be harmonized.

In the early 1900s, the idea of fragmenting and typing instructional goals took root and grew to dominate the literature and practice of instructional technologists throughout much of the $20^{\text {th }}$ century. Emphasis on using objectives (Bruner, 1970; Glaser, 1966; Tyler, 1949) spawned rules

\footnotetext{
${ }^{1}$ The author appreciates feedback from Brad Hokanson and the participants in the Symposium review process on earlier drafts of this paper. Thanks for some wonderfully enlightening conversations. I have made changes. The errors that remain are mine.
} 
for writing objectives (Mager, 1962), and the two popular objective typologies of Bloom and Gagne (Bloom \& Krathwohl, 1956; Gagné, 1965, 1970, 1977, 1985). Today these taxonomies ${ }^{2}$ are taught to new designers as "given" wisdom, and the teacher's opinion about which one is most suitable is often imprinted on the opinions of the designer. This creates a loyalty war that is unnecessary and counterproductive. This paper suggests that we should bend our efforts in the direction the original taxonomists were headed with their work, beyond the restrictions of the taxonomies in their present form, to search for the overarching, unifying theme they were seeking. This paper proposes that finding that theme will unite the apparently disparate taxonomies. I recommend that we can use the concept of skilled performance to accomplish this.

In 1956 Bloom's family of goal typologies for the cognitive, affective, and psychomotor domains was originally motivated by the desire to discriminate levels of behavior for test construction (Bloom \& Krathwohl, 1956; Krathwohl, Bloom \& Masia, 1964; Harrow, 1972). At roughly the same time, Gagné was interested in specifying conditions that facilitated different types of learning identified from more basic learning research. The taxonomies of both Bloom and Gagné are appropriately considered works in progress, as evidenced by persistent efforts to expand and elaborate them. In the cases of both the Bloom and the Gagne taxonomies, this would also include integrating affective and psychomotor goal types with the cognitive and intellectual types. Anderson and her team of experts elaborated and expanded the work of Bloom in the cognitive domain (Anderson \& Krathwohl, 2001; Krathwohl et al, 2001). Gagné himself created multiple versions of his taxonomy of learning types, continuing to develop the theme after the publication of the fourth and last edition of his Conditions of Learning series.

There has been surprisingly little curiosity about why Gagné's followers stopped elaborating his system of learning goals after his death. Gagné himself would doubtless have continued building on the foundation laid. His taxonomic work grew in a pattern that seemed to be reaching toward the most expansive summation of the human learning phenomenon. Similarly, the revision of Bloom's cognitive domain taxonomy by Anderson and her team is suggestive: we should be curious about what a similar revision of the affective and psychomotor domains would look like and how these domains might be integrated.

Given this historical pattern of taxonomy expansion and elaboration, there is reason to believe that the early taxonomists would disapprove of the inflexible way in which their ideas are treated today. Many designers come away from university and textbook training with the impression that the taxonomies represent a settled issue. New designers are not taught to ask about the absence of current research on instructional objectives, so designers are left to choose a favorite taxonomy, create their own approach, or do without. For practical purposes, most designers apply objectives as a tool to communicate with clients, and at some level taxonomies work for this purpose. They provide the designer with a formula and the client with a comforting feeling. Many designers pursue their trade with a "follow the process" mindset, including with respect to

\footnotetext{
${ }^{2}$ It is important to note that although Bloom used the term "taxonomy" in the title of his work, Gagne distanced himself from the term. Despite that, it has stuck anyway: "No particular reason exists to think of these five different learning outcomes as constituting a taxonomy or as having been derived for that reason" (Gagné, 1984, p. 384). Gagné preferred the phrase "useful categories of human performance" instead. This gives evidence to my thesis.
} 
objectives. But over time, what began in the minds of the early taxonomists as an exciting exploration of new territory became a trip around the block.

Even in these frozen forms might thaw if we were to revisit the original explorations of Bloom and Gagné and pursue their questions with fresh energy. Reopening the taxonomy question could possibly lead to a unification of the two major taxonomies and a reconsideration and revitalization of the theme of high-level instructional goals, how they are created, and their relationship to instructional methods and assessment. Despite the changing landscape of learning theory, designers still must supply a rationale for their designs based on learning goals.

A Way Forward and A Proposal

We might begin with observing how instructional designers tend to use taxonomies today. Many if not most designers find goal taxonomies useful to some degree, and most have a favorite, but these are often adapted and expanded by the designer for the designer's particular personal use. For example, a designer creating training for emergency medical technicians (EMTs) will normally identify the individual concepts, principles, and procedures that make up the subjectmatter using some form of task analysis and perhaps the taxonomized learning objective types.

However, most designers also realize that proper assessment of higher-level capabilities following training requires the learner to flexibly perform extended sequences of procedures under real-world conditions, following correct principles and using "good" judgment: the learner must demonstrate some level of skill. Often this level of assessment requires specialized practice and assessment environments, such as simulators or realistic drills.

Assessment at this level involves performance organized at a level above what is contained in the Bloom or Gagné taxonomies. In this instance, many designers dealing with complex subjectmatter areas develop one or more additional objectives categories that account for this level of performance. These categories represent a step "beyond content" as the theme of this conference suggests. Perhaps one approach to getting beyond content is to consider the unfinished business - higher-level knowledge that makes skilled performance possible.

Designers use this higher level of goal specification to design performance challenges in the form of practical problems that require integrated application of many of the taxonomized knowledge types by learners in a fluent performance that requires problem-solving, adaptation to unexpected circumstances, improvisation, and self-monitoring and self-correction. This is skilled performance. A more robust literature for instructional designers on skill as a form of learning and assessment goal — a goal that integrates the intellectual, the emotional, and the motor aspects of performance, among other things - would help individual designers accept the value-added of a coherent doctrine of skill learning, instruction, and assessment that subsumes the value of their taxonomies without destroying them.

There exists outside of the field of instructional technology (IT) a robust literature on the subject of skill training and assessment. What is lacking is the adoption and absorption of this literature by the IT field and its appropriation for the research and development purposes. The topics of skill learning, instruction of skills, and high-level instructional design skills are highly relevant to 
the practice of instructional technology, but they occupy a proportionally very small segment of the IT literature and design practice. This paper proposes that:

1. The field of instructional technology should pay greater attention to the concept of skilled performance, which includes seamless real-time integration of cognitive skills, motor skills, emotive and conative states, value sets, and ethical principles.

2. The field of instructional technology should place greater emphasis on research on instructional practices that can be used for establishing and maintaining skilled performance, and it should expand the range and quality of literature on the establishment of skills that is available to new designers during their professional preparation.

3. The field of instructional technology should teach design practice as a flexible and judgment-intensive skilled performance — a skill—rather than as processes to be followed.

This program of action will increase the relevance and applicability of instructional technology research and encourage the use of flexible and adaptive instructional design practices.

\section{What is Skill?}

Skill is the fabric of our everyday behavior. It represents the unfragmented flow of constantlyadaptive human behavior. It incorporates within it all other taxonomized forms of performance and adds the dimensions of judgment, constructive and helpful attitudes, and ethical behaviors. If skill is involved with taxonomies at all, then it should be considered at the apex of all taxonomic structures: the culmination of what taxonomies were leading to in the first place. Skills are never really "mastered". They are acquired and either grow or decay over time. The study of how this occurs, how designers can themselves become skilled practitioners of their own craft is worthy of our concentrated study. In fields where instruction concentrates on skills, the literature normally refers to the creation of "expertise", a connection made by Amirault and Branson (Amirault \& Branson, 2006). Gagné and Merrill were collaborating in this direction in their writing on "enterprise" learning (Gagné \& Merrill, 1990).

The term expertise normally denotes a very high level of skilled competence, but expertise begins with the learning of basic skills, so progress toward expertise is relative to where the performer started. There seems to be no firm dividing line between skill and expertise. In this paper I use the term skills, but I will also draw on the literature of expertise and expert performance. It is possible that Gagné in his continued expansions of his taxonomic system was moving in the same direction as Bruner, who himself was trying to describe a species of human activity typical of the flow of performance in everyday life - skilled performance. Bruner's description proposed that "what is learned is competence, not particular performances" (Bruner, 1970, p. 67). There is in Bruner's description a type of performance and a degree of adaptability and fluidity of performance that the work of the taxonomists point to but do not capture. The learning of this type of performance requires conditions congenial to this type of learning. Instructional technology as a field must embrace a technology of designing for and instructing skilled performance. 
Many fields outside of instructional technology have explored the development of skilled performance and expend much of their research and development energies to study the establishment of skills. This includes the fields of reading research and reading instruction, writing and composition skills, business entrepreneurial skills, foreign language skills, sports, industrial/technical skills, and research in cognitive skills. The interests of instructional technology should be connected with and felt in all of these areas, but the progress and findings of these other fields is not a primary theme in the IT literature, despite the fact that the learning of complex skills often involves heavy use of advanced hardware, software, and instructional technologies. Excellent resources describing research on skills and expertise in other fields can be found in The Nature of Expertise (Chi, Glaser \& Farr, 1988) and The Cambridge Handbook of Expertise and Expert Performance (Ericsson et al, 2006).

\section{Skilled Performance as a Unique Class of Learning}

What makes skilled performance sufficiently distinctive that it should be considered a class of learning and instruction by itself, complete with distinctive methods of instruction?

1. Skilled performance consists of the performance of multiple, subordinate, constituent skills in a sequence sculpted by conditions at the moment of performance. The constituent skills that make up a skill are themselves skills that must be learned before they can be combined into longer segments of competent performance. It is interesting to note that Gagné attached the term "skill" to some of his categories.

2. Because it is constituted and executed contingent upon circumstances surrounding the performance, skilled performance is adaptive. Performance plans change to adapt to changing conditions in the performance environment moment by moment.

3. Because skilled performances are composed at the moment of performing, a particular kind of performance, such as returning a ping pong ball or dancing a Tango, is performed differently from occasion to occasion, even if only in minute details. The performance of skill involves constant monitoring by the performer of the conditions surrounding performance, and of the ongoing quality of the performance itself. Information gained from monitoring conditions is used by the performer to adjust the performance in realtime.

4. Skilled performance is learned through repeated practice that includes knowledge of the quality of the performance (feedback) provided either during or following performance. The first performance of a skill normally involves unfamiliar actions, mental calculations, emotions, and values on the learner's part that are unfamiliar, so initial performances may be halting and error-prone. As these disparate elements of an acceptable performance become integrated in the learner's mind, performance can become more fluid.

5. As a performer observes his or her own performance of a skill, it often leads to new learning that can be used for the improvement of future performances. New methods of 
performance can be invented by a performer spontaneously, leading to increased skill, efficiency, or effectiveness. Skills can also be discovered serendipitously through accidental or unplanned experiences and even through mistakes that produce unexpected outcomes.

6. Excellence in skilled performance involves the exercise of judgment and agency, based on self-observations or feedback over a large number of performances.

7. It may be necessary in some cases for a performer to concentrate practice temporarily on a subordinate component skill in isolation, under less than real-world conditions in order to improve performance that otherwise hinders the performance of a complete skill.

8. Skill is often learned in the presence of a coach or mentor, who provides feedback on performance details the performer cannot observe. A coach may also suggest improvements, which the performer may choose to adopt, or not. Attaining the highest levels of mastery or artistry always requires external assistance.

9. Skilled performance has cognitive, physical, and attitudinal or emotional components, as well as conative and ethical dimensions. Competent performance requires that all of these factors be present at an acceptable level. Assessment of skilled performance must therefore take into account and judge all of these factors. Instruction in skilled performance must provide for the integration of these concerns with practice during learning, rather than dealing with them as separate topics.

10. Skilled performance may take place at barely acceptable levels or it may advance to levels of mastery or even artistry. Higher levels of attainment require using disciplined training methods over a long period of time. Acquisition of a skill is a process of constant learning that often requires scaffolding that fades over time.

11. Confidence is an essential part of skilled performance. Lack of confidence can lead to errors. Continued failure experiences can lead to demoralization, which the performer can turn inwardly into a negative self-judgment. Likewise, a sufficient number of success experiences, as perceived by the performer, can increase confidence and encourage pursuit of further levels of skill. Some scaffolding actions on the part of the instructors contribute to calming fears and raising confidence.

12. There is an element of introspection before and after skilled performance that even a highly-skilled learner can use to improve future performance through anticipation, mental rehearsal, self-assessment, and self-correction.

13. Skilled performances become automated to the extent that more than one skill can be performed contemporaneously, and under conditions of divided attention. In this way, separate skills such as walking can be interleaved with other skills such as chewing gum. Skill performance can also become habitual to the extent that performance is initiated without conscious awareness. 
14. Learners can become aware of their own learning processes to the extent that they can manage their own learning by selecting and pursuing their own new skills.

These characteristics of skilled performance taken together set skilled performance in a class by itself, related to, but apart from the performances found in the standard taxonomies. Many of the taxonomized learning types of both Bloom and Gagné are fragments of higher-level skills. It is important to note that both taxonomies consider themselves at least partially cumulative and hierarchical. Many of the taxonomized behaviors can be learned in isolation and still not be very useful by themselves in everyday settings. Skilled performance provides the context that makes taxonomized behaviors useful in everyday activity.

\section{Revisiting the Taxonomies}

The distinctive quality of skilled performance learning is found in the transition points between the completion of one lower-level, constituent performance and the selection of the next. This, of course, is a gross oversimplification, and skill performance is clearly more complex than stopping one activity and deciding to take up another. However, there is a kind of learning that enables the learner to select and integrate sequences of performances in an adaptive manner. This is a description of skilled performance as a unique class of instructional goal, and the Bloom and Gagné taxonomies are both compatible with this definition.

David Krathwohl (2002), while describing the revision of the original Bloom taxonomy explained that one of the purposes of the original taxonomy was as a "means for determining the congruence of instructional objectives, activities, and assessments in a unit, course, or curriculum..." (Krathwohl, p. 212). Just as the taxonomy categories can serve as a touchstone for comparing equivalences of individual objectives, this paper speculates that they could also be used as a touchstone for building links with the goal categories of other taxonomic systems.

A move in that direction may already have been taken in the revision of the Bloom taxonomy, in which Krathwohl participated. The original version of Bloom's categories represented generalized, content-agnostic skills, unlike Gagné's, which represented content-specific skills (e.g., associations, S-R chains, concepts, rules, principles, depending on the version of his taxonomy). Gagné's taxonomies were formed asking the question, "What is learned?". His multiple answers to the question over time showed that he was trying to derive categories from the best available research knowledge. At the same time, his categories became centered on types of learned entity. He persisted in describing the association because it was, he felt, a basic learned structure. He identified rules and procedures because he felt there were some learned entities of that type.

The Anderson-Krathwohl revision of Bloom's cognitive taxonomy involved the creation of a matrix that crosses each generalized mental process with specific content categories very much like Gagné's. Krathwohl (2002) described this as giving the verb (the behavior) a noun phrase (the type of knowledge acted upon by the generalized performance types), as was already implicit in the original taxonomy. The two taxonomies that designers previously saw as being so different moved closer to each other with this revision of Bloom. Similarly, David Merrill, in an attempt to elaborate on Gagné's categories, used this same approach when he formed a matrix of 
instructional goal types by crossing the content types (fact, concept, procedure, and principle) with the mental process types (find, use, remember generality, and remember instance) (Merrill, 1994, see pp. 111-120). Over a period of years, Merrill's taxonomy underwent multiple changes as well.

Conclusion

This paper began with a discussion of the unfinished business of the learning taxonomists, noting that many designers consider the differences between the Bloom and Gagné taxonomies so great that they feel they must choose one or the other or else blend the two and make creative additions of their own. It is highly likely that an analysis more detailed than can be accomplished in this paper would substantiate the claim that the taxonomies are in fact highly compatible in their revised forms and that both are compatible with and can supply primitives to for integration within the super-category of skilled performance. This view deserves more elaboration, but it represents a question of much importance to the field of instructional technology.

IT should pay greater attention to the concept of skilled performance, and the proposition that research on skill learning should become an important research topic in IT follows naturally. My third proposition, that design activity should be taught within IT as a skilled performance rather than a procedure, would represent a major step forward. What is needed is a better description of design skill. Much recent IT literature has targeted that goal (see Gibbons, 2014).

\section{References}

Amirault, R. J. \& Branson, R. K. (2006). Educators and expertise A brief history of theories and models. In K. A. Ericsson, N. Charness, P. J. Feltovich \& R. R. Hoffman, The Cambridge Handbook of Expertise and Expert Performance. Cambridge, UK: Cambridge University Press, 69-86.

Anderson, L. W., Krathwohl, D. R., Airiasian, W., Cruikshank, K. A., Mayer, R. E., \& Pintrich, P. R. (2001). A taxonomy for learning, teaching and assessing: A revision of Bloom's Taxonomy of educational outcomes: Complete edition. NY: Longman.

Bloom, B.S. \& Krathwohl, D. R. (1956) Taxonomy of Educational Objectives: The Classification of Educational Goals, by a committee of college and university examiners. Handbook I: Cognitive Domain. New York: David McKay Co.

Bruner, J. (1970). The skill of relevance or the relevance of skills. Saturday review of literature, 53(14), 66-8, 78-9.

Chi, M. T. H., Glaser, R. \& Farr, M. J. (1988). The nature of expertise. Hillsdale, NJ: Lawrence Erlbaum Associates.

Ericsson, K. A., Charness, N., Feltovich, P. J. \& Hoffman, R. R. (2006). The Cambridge Handbook of Expertise and Expert Performance. Cambridge, UK: Cambridge University Press. 
Gagné, R. M. (1965). The conditions of learning. New York: Holt, Rinehart \& Winston.

Gagné, R. M. (1970). The conditions of learning, (2 ${ }^{\text {nd }}$ ed.). New York: Holt, Rinehart \& Winston.

Gagné, R. M. (1977). The conditions of learning, ( $3^{\text {rd }}$ ed.). New York: Holt, Rinehart \& Winston.

Gagné, R. M. (1985). The conditions of learning, ( $4^{\text {th }}$ ed.). New York: Holt, Rinehart \& Winston.

Gagné, R. M. (1984). Learning outcomes and their effects: Useful categories of human performance. American psychologist, 39(4), 377-385.

Gagné, R. M., \& Merrill, M. D. (1990). Integrative goals for instructional design. Educational Technology Research and Development, 38(1), 23-30.

Gibbons, A. S. (2014). Eight views of instructional design and what they should mean to instructional designers. In B. Hokanson and A. S. Gibbons (Eds.), Design in educational technology: Design thinking, design process, and the design studio. New York: Springer.

Glaser, R. (1966). Psychological bases for instructional design. AV communication review, 14(4), 433-449.

Harrow, A. J. (1972). A taxonomy of the psychomotor domain. New York: David McKay Co. Krathwohl, D. R. (2002). A revision of Bloom's taxonomy: An overview. Theory into practice, 41(4), 212-218.

Krathwohl, D. R. \& Bloom, B. S. (1964). Taxonomy of Educational Objectives. Book 2: Affective Domain. New York: David McKay Co.

Mager, R. F. (1962). Preparing instructional objectives. Belmont, CA: Fearon Publishers.

Merrill, M. D. (1994). A descriptive component display theory. In M. D. Merrill and D. G. Twitchell (Eds.), Instructional design theory. Englewood Cliffs, NJ: Educational Technology Publications, 111-157.

Tyler, R. W. (1949). Basic principles of curriculum and instruction. University of Chicago press. 